\title{
The Effects of a Self-Care Educational Program Based on Orem's Theory on the Quality of Life of Elderly People Residing in Nursing Homes
}

\author{
Leila Hashemlu, ${ }^{1, *}$ Masumeh Hemmati Maslakpak, ${ }^{2}$ and Farzaneh Bagherie ${ }^{1}$ \\ ${ }^{1}$ Faculty of Nursing and Midwifery, Uremia University of Medical Sciences, Uremia, IR Iran \\ ${ }^{2}$ Maternal and Childhood Obesity Research Center, Urmia University of Medical Sciences, Urmia, IR Iran \\ "Corresponding author: Leila Hashemlu, Faculty of Nursing and Midwifery, Uremia University of Medical Sciences, Uremia, IR Iran. E-mail: 1.hashemloo@yahoo.com
}

Received 2014 January 24; Revised 2015 August 03; Accepted 2015 August 29.

\begin{abstract}
Background: Given the growing population of elderly individuals, developing strategies for improving their quality of life seems crucial. Quality of life improvement is the essence of all healthcare activities. Quality of life has a negative relationship with age. Elderly people lose their abilities and become vulnerable and thus, need special attention and support.

Objectives: The present study was designed and undertaken to examine the effects of a self-care educational program based on Orem's self-care theory on the quality of life of nursing home residents.

Methods: This quasi-experimental study was performed on 50 elderly individuals, who resided in nursing homes located in Urmia, Iran. The participants were conveniently selected and randomly allocated to the control and the experimental group, 25 to each group. For the elderly people in the experimental group, a self-care educational program was implemented with four to six, 30 - to 45-minute sessions. Educational contents were developed based on the participants' educational needs. Quality of life assessment was performed before and one month after the intervention using the world health organization quality of life questionnaire. The data were analyzed by employing the SPSS (v. 16.0) software and independent-sample t, Chi-square, Wilcoxon, and Mann-Whitney U tests

Results: The Mann-Whitney U test showed a significant difference between the groups regarding the posttest values of quality of life total score and the scores of the physical and the psychological health domains of quality of life $(\mathrm{P}=0.001)$. In other words, the implemented self-care educational program significantly improved the participants' quality of life.

Conclusions: Implementing the self-care educational program was effective for improving elderly people's quality of life. Such programs can be used as effective strategies to improve nursing home residents' quality of life. Given the progressive nature of age-related problems, using self-care models is of grave importance.
\end{abstract}

Keywords: Orem's Self-Care Model, Quality of Life, Elderly People

\section{Background}

According to the United Nations, once the population of people older than 60 years exceeds $7 \%$ in a community, that community is considered as aged. The last statistics provided by the Iranian ministry of health and medical education in 2011 indicated that with an elderly population of about $8.2 \%$, Iran is an aged country. It is estimated that the Iranian elderly population will reach $10.5 \%$ and $21.7 \%$ by years 2025 and 2050, respectively $(1,2)$.

Healthy aging is the absolute right of all humans. Such a right adds to the importance of the aging phenomenon and the prevention of age-related problems. Because of their great physical weaknesses and vulnerability, elderly people need more comprehensive care (3).

Some elderly people reside in nursing homes. nursing homes residents (NHR) have special needs and problems, which increase healthcare costs (4). Studies have shown that aging increases healthcare costs exponentially $(5,6)$.

Aging reduces mobility and income and increases the prevalence of physical and mental problems (7). Numerous physical and mental problems during aging impair the quality of life (QOL) of elderly people (8). The world health organization defined QOL as “individuals' perception of their position in life in the context of culture and value systems in which they live and in relation to their goals, expectations, standards and concerns" (9). Consequently, health-promoting behaviors assume an added importance during aging due to their potential effectiveness in maintaining elderly people's functionality and independence and improving their QOL (8).

Simmons (2009) noted that individuals' active participation in maintaining their own health improves their health and QOL (10). Demura and Sato quoted Coil et al.

Copyright ( $)$ 2015, Birjand University of Medical Sciences. This is an open-access article distributed under the terms of the Creative Commons Attribution-NonCommercial 4.0 International License (http://creativecommons.org/licenses/by-nc/4.0/) which permits copy and redistribute the material just in noncommercial usages, provided the original work is properly cited. 
(2003), saying that compared with people, who have a sedentary lifestyle, people with active lifestyle are at lower risk of depression and have greater life satisfaction, more positive social interactions, more confident relationships, and better QOL (11). Physical activity and mental health are two significant predictors of elderly people's QOL (11). Osada et al. (1995) mentioned that elderly people, who are able to perform activities of daily living, physical activities, and recreational and leisure-time activities, have lower levels of depression and higher levels of QOL (12).

About $58 \%$ of people aged 65 or more need help for doing activities of daily living (13). Educational and supportive strategies and programs are needed to maintain their independence and improve their self-care ability. Conceptual models, which guide nurses' practice, have a significant role in supporting patients' self-care ability. Orem's self-care theory (OSCT) is among the most coherent selfcare theories. It provides a clear clinical guideline for planning and implementing self-care programs (14). Orem considered humans as self-care agents, who perform all health-related activities in order to protect their health and lives and gain a sense of persistent well-being. Given the rapid medical advances, increased healthcare costs and inadequate recreational and healthcare facilities for the growing global population, the concept of self-care assumes a paramount importance (15). Elderly people need help for doing their self-care activities (16). On the other hand, healthcare professionals need to pay special attention to elderly people's QOL. In other words, healthcare programs are considered beneficial only when they can improve elderly people's QOL (17). Consequently, developing effective programs and strategies is essential to improve elderly people's QOL and cut healthcare costs.

One of the factors, which can dramatically affect elderly people's QOL, is their place of residence (18). Nursing Homes Residents are less self-confident and have poorer self-care status compared with elderly people, who live in private houses (19). Sil et al. (2003) reported that the general health of elderly people, who live in private houses, is significantly better than NHRs (20).

Although improvement of elderly people's QOL is among the primary goals of health promotion initiatives, great doubts still exist about the positive effects of physical ability enhancement on the improvement of other aspects of QOL (13). Besides, there is no credible information concerning the effects of OSCT on the QOL and health problems of NHRs in Iran.

\section{Objectives}

The present study was designed and undertaken to examine the effects of an OSCT-based self-care educational program on NHRs' QOL.

\section{Methods}

This was a pretest-posttest controlled quasiexperimental study. The study setting was all four nursing homes located in Urmia, Iran. In total, 98 elderly people resided in these nursing homes at the time of the study. We recruited a convenient sample of 50 NHRs from Al-Zahra, Khaneye Sabz, Araa, and Ferdows nursing homes (with sixteen, seventeen, eight, and nine individuals, respectively). The inclusion criteria were age of 65 or older and having neither dementia nor hearing and visual impairments. They were excluded if they failed to attend two consecutive educational sessions or one fourth of all sessions.

Primarily, written consent was obtained from all participants. Then, they were asked to complete a need assessment questionnaire (NAQ). Thereafter, they were allocated to two 25-person groups. The groups were matched with each other regarding the type of nursing homes (private or public), participants' gender and educational status, and their scores on the NAQ. After that, the groups were randomly allocated to either an experimental or a control group through tossing a coin.

Three questionnaires were used for data gathering. The first was a demographic questionnaire, which consisted of items on participants' age, gender, educational and marital status, job, type of nursing home, length of stay in nursing homes, source of income and number of visits. The second questionnaire was a researcher-made 44item NAQ, which was developed based on Orem's self-care theory and through performing a literature review on elderly people's needs. This questionnaire included three domains of universal, developmental, and health-deviation self-care requisite. Each item was scored dichotomously as zero or one. Therefore, the total score of the NAQ ranged from 0 to 44. According to our statistical adviser, the participants, who obtained scores of 0 -15, 16-30 and 31 - 44, were categorized as, respectively dependent, semi-dependent, and independent for performing self-care activities. The face validity of the NAQ was assessed through asking ten elderly people to assess the simplicity, clarity and wording of its items. On the other hand, we evaluated the content validity of the NIQ through inviting fourteen experts to carefully read its items and write their comments in detail. The items were then revised accordingly. The Cronbach's alpha of the NAQ was 0.89 .

The third questionnaire was a brief version of the world health organization quality of life questionnaire (WHOQOL-BREF). It comprises of 26 items, from which two items assess general QOL. The remaining 24 items of the 
scale fall into four domains including physical health, psychological health, social relationships and environment (21). Nejat et al. (2006) translated the WHOQOL-BREF to Persian and assessed its psychometric evaluation. They reported that the Persian WHOQOL-BREF had optimal validity. Moreover, they found that the test-retest correlation coefficients for the physical health, psychological health, social relationships, and environment domains of the scale were $0.77,0.77,0.75$, and 0.84, respectively. Besides, they reported that the Cronbach's alpha values of the WHOQOLBREF domains were up to 0.84 (22). We also found that the Cronbach's alpha of the scale was 0.92 .

After identifying the participants' self-care needs, an OSCT-based self-care educational program was developed and implemented to fulfill the identified needs. The content of the program was obtained from medical and nursing textbooks. The program consisted of partially compensatory and supportive-educative nursing systems and helped the participating elderly engage in and perform self-care activities independently. In the supportiveeducative nursing systems, counseling and educational services were provided to the participants based on their needs while in the partially compensatory system we helped the participants perform self-care activities and fulfill their self-care needs. Education was provided for the participants through using lectures, Power-point presentations, face-to-face personal education, and role-play methods. The number of educational sessions depended on the educational status of the participants and ranged from four to six. The sessions lasted 30 to 45 minutes (23). At the end of the program, a booklet containing the information was provided to the participants and the staff of the study setting. The staff could use the content of the booklet to support the participants. After the intervention, the elderly people in the experimental group performed selfcare activities based on the education they had received for one month (24). During this one-month period, we attended the study setting or made telephone contacts with the participants in order to supervise and support their engagement in self-care activities and also to answer their questions. In the control group, the participating elderly people obtained no self-care education and only received routine care services provided to all elderly people, who resided in the study setting. Finally, a posttest was given to the participants in both groups. After the study, we provided the elderly in the control group with the same educational sessions provided for the participants in the experimental group for the sake of ethical considerations.

The gathered data were analyzed using the SPSS (v. 16.0) software and the independent-sample t, Chi-square, Wilcoxon, and Mann-Whitney U tests at a significance level of less than 0.05 .

\section{Results}

Most of the participants in the control and the experimental groups were female ( $88 \%$ and $84 \%$, respectively). The means of their age were $73.28 \pm 9.15$ and $73.8 \pm 10.2$ years, respectively. The results of the chi-square test illustrated that there was no significant difference between the groups regarding the participants' age, length of stay in nursing homes, number of visits, gender, source of income, and educational, employment and marital status (P $>0.05$; Table 1 ).

In the control group, $48 \%$ of the elderly people had minimal self-care needs, $44 \%$ had moderate needs, and $8 \%$ had considerable needs. These values in the experimental group were $44 \%, 52 \%$ and $\% 4$, respectively. The chi-square test showed that the difference between the groups regarding self-care needs was not statistically significant $(\mathrm{P}=0.76$; Table 2).

The results of the Wilcoxon test showed that in the control group, there was no significant difference between the pretest and the posttest values of QOL and its domains. However, in the experimental group, the posttest values of the total QOL score and the scores of the physical and the mental health domains of QOL were significantly higher than the corresponding pretest values (Table 3 ). The MannWhitney U test also showed that after the study, the difference between the study groups regarding total QOL score and the scores of the physical and mental health domains was statistically significant (Table 3 ).

\section{Discussion}

Given the increasing longevity of the global population, the greatest healthcare challenge in the present century is to live a life of higher quality. The findings of the present study revealed that our OSCT-based self-care educational programs were effective in improving elderly people's total QOL score and the scores of the physical and the psychological health domains of QOL. This is in agreement with the findings reported by Mirsaeedi et al. (2013). They found that the mean scores of the physical and the psychological health domains of elderly people's QOL significantly increased after their self-care program (25). Baraz et al. (2009) also found that their self-care educational program was effective in improving all aspects of QOL among elderly people, who lived in Masjed Soleyman, Iran (23). The difference between our findings and the findings reported by Baraz et al. (2009) (23) can be attributed to the fact that their participants lived in private houses while our study was done on NHRs. Compared with elderly people, who lived in private houses, NHRs usually experience more problems. Heidari and Shahbazi (2012) also reported 
Table 1. Comparison of the Study Groups Regarding the Participants' Demographic Characteristics

\begin{tabular}{|c|c|c|c|c|c|}
\hline \multirow[t]{2}{*}{ Variable } & \multicolumn{2}{|c|}{ Control Group } & \multicolumn{2}{|c|}{ Experimental Group } & \multirow[t]{2}{*}{ The Results of the Independent-Sample t Test } \\
\hline & Mean & Standard Deviation & Mean & Standard Deviation & \\
\hline Age & 73.28 & 9.15 & 73.8 & 10.2 & $\mathrm{P}=0.84$ \\
\hline Length of stay in nursing homes & 3.3 & 2 & 3.2 & 1.7 & $\mathrm{P}=0.8$ \\
\hline Number of visits & 9.8 & 13 & 12.8 & 12.6 & $P=0.52$ \\
\hline Variable & No. & $\%$ & No. & $\%$ & The results of the Chi-square test \\
\hline Gender & & & & & $\chi^{2}=0.17, \mathrm{df}=1, \mathrm{P}=0.68$ \\
\hline Male & 3 & 12 & 4 & 16 & \\
\hline Female & 22 & 88 & 21 & 84 & \\
\hline Marital status & & & & & $\chi^{2}=3.2, \mathrm{df}=3, \mathrm{P}=0.37$ \\
\hline Married & 3 & 12 & 6 & 24 & \\
\hline Single & 1 & 4 & 2 & 8 & \\
\hline Divorced & 4 & 16 & 1 & 4 & \\
\hline Spouse's death & 17 & 68 & 16 & 64 & \\
\hline Nursing homes & & & & & $\chi^{2}=0.25, \mathrm{df}=3, \mathrm{P}=0.97$ \\
\hline Al-Zahra & 9 & 36 & 9 & 36 & \\
\hline KhaneyeSabz & 10 & 40 & 9 & 36 & \\
\hline Araa & 4 & 16 & 4 & 16 & \\
\hline Ferdows & 2 & 8 & 3 & 12 & \\
\hline Educational status & & & & & $\chi^{2}=0.23, \mathrm{df}=2, \mathrm{P}=0.89$ \\
\hline Illiterate & 14 & 56 & 15 & 60 & \\
\hline Below diploma & 8 & 32 & 8 & 32 & \\
\hline Diploma and higher & 3 & 12 & 2 & 8 & \\
\hline Employment status & & & & & $\chi^{2}=0.67, \mathrm{df}=2, \mathrm{P}=0.72$ \\
\hline Housewife & 9 & 36 & 9 & 36 & \\
\hline Unemployed & 11 & 44 & 13 & 52 & \\
\hline Retired & 5 & 20 & 3 & 12 & \\
\hline Source of income & & & & & $\chi^{2}=0.15, \mathrm{df}=2, \mathrm{P}=0.93$ \\
\hline Charities & 9 & 36 & 9 & 36 & \\
\hline Family & 12 & 44 & 13 & 48 & \\
\hline Personal income & 5 & 20 & 4 & 16 & \\
\hline
\end{tabular}

Table 2. Comparing the Groups Regarding Their Self-Care Needs

\begin{tabular}{l|c|c|c}
\hline The Level of Needs & Control Group, No. (\%) & Experimental Group, No. (\%) & \multirow{2}{*}{ The Results of the Chi-Square Test } \\
\cline { 1 - 3 } Minimal, Dependent & $12(48)$ & $13(52)$ & \\
\cline { 1 - 3 } Moderate, Semi-dependent & $11(44)$ & $1(4)$ & 0.76 \\
\cline { 1 - 2 } Considerable, Dependent & $2(8)$ & $25(100)$ & \\
\hline Total & $25(100)$ & \\
\hline
\end{tabular}


Table 3. Comparing the Groups Regarding the Scores of World Health Organization Quality of Life Questionnaire (WHOQOL-BREF) and its Subscales

\begin{tabular}{|c|c|c|c|c|}
\hline \multicolumn{2}{|c|}{ Domains } & Before, Mean \pm SD & After, Mean \pm SD & The Results of the Wilcoxon Test \\
\hline \multirow{5}{*}{ Experimental group } & Physical health & $22.12 \pm 5.38$ & $23.50 \pm 5.21$ & 0.009 \\
\hline & Psychological health & $19.20 \pm 3.48$ & $20.12 \pm 3.35$ & 0.02 \\
\hline & Social relationships & $8.08 \pm 1.88$ & $8.12 \pm 2.04$ & 0.86 \\
\hline & Environment & $27.37 \pm 4.14$ & $28.29 \pm 4.12$ & 0.08 \\
\hline & Total QOL & $76.79 \pm 10.72$ & $80.04 \pm 11.29$ & 0.02 \\
\hline \multirow{5}{*}{ Control group } & Physical health & $21.88 \pm 5.68$ & $21.80 \pm 5.64$ & 0.69 \\
\hline & Psychological health & $18.26 \pm 3.80$ & $17.84 \pm 3.62$ & 0.07 \\
\hline & Social relationships & $8.50 \pm 2.28$ & $8.58 \pm 2.24$ & 0.56 \\
\hline & Environment & $25.84 \pm 4.75$ & $26.38 \pm 4.43$ & 0.06 \\
\hline & Total QOL & $74.50 \pm 13.84$ & $74.61 \pm 13.70$ & 0.95 \\
\hline
\end{tabular}

that their self-care training program was effective in improving elderly people's QOL (26). It seems that our selfcare educational intervention enhanced elderly people's QOL through improving their self-control and empowering them for doing self-care activities. The insignificant effect of the study intervention on social relationships and environmental domains of QOL may be due to the participants' residence in nursing homes and thus, their limited participation in social activities and their limited control over their immediate environment.

Our findings are also consistent with the findings of studies conducted in other parts of the world. Dickson et al. (2012) did a study in New York and found that selfcare program, physical exercise and engagement in workrelated activities significantly improved QOL. They also noted that increased self-care ability can enhance treatment adherence and alleviate physical and psychological symptoms (27). In addition, Lord and Castal (2004) found that self-care program and physical exercise boosted muscular strength, improved body balance, and enhanced all domains of QOL (28).

Our findings revealed that self-care education was effective in improving the psychological and the physical aspects of QOL while it had no significant effect on its social relationships and environmental domains. Quality of life is affected by many factors, most of which are out of the individuals' control. These findings are due to the fact that elderly people, who live in nursing homes, have limited control over their social relationships and environment. Kane (20010) also reported that compared with elderly people, who live in private houses, NHRs have lower psychosocial status, experience more health problems, and have limited self-care ability (29).

One of the study limitations was the effects of the par- ticipants' physical and psychological status on their ability to complete the study questionnaires. Furthermore, the participants might have had poor adherence to the provided educations and self-care activities.

\subsection{Conclusion}

The findings of this study indicate the effectiveness of self-care education in improving QOL and its physical and psychological health domains. When there is no option but to take elderly people to nursing homes, it is necessary to implement measures to improve their QOL. From the results of this study, it can be suggested that self-care programs need to be developed based on elderly people's educational needs and status as well as their ability to comprehend and use intended educations. Programs, which are developed in this way, are more likely to promote elderly people's participation in self-care activities, to improve their QOL, and to help them have a calm and pleasant life.

\section{Acknowledgments}

This article was part of a master's thesis at Urmia University of Medical Sciences, Urmia, Iran. Hereby, we thank the administrators of the university, the managers and the staff of the study setting, and the elderly people who agreed to participate in our study.

\section{References}

1. Teymoori F, Dadkhah A, Shirazikhah M. Social welfare and health (mental, social, physical) status of aged people in Iran [ in Persian ]. East J Age Ageing. 2006;3(1):39-45.

2. Taheri P. Reported in elderly populations. Tehran: Ministry of Health and Medical Education; 2012. 
3. Bolander WB, Lucmand SS. Basic nursing and psychologic approach. Philadelphia: WB Saunder; 2004.

4. Saheb Alzamani M, Mehrabian F, Asgharzadeh AR. Determine the satisfaction level of services which are given to elderly in Rasht Disabled and Elderly Residential [in Persian]. J Guilan Univ Med Sci. 2009;17(68):34-41.

5. Dausch JG. Aging issues moving mainstream. J Am Diet Assoc. 2003;103(6):683-4. doi:10.1053/jada.2003.50155. [PubMed: 12778036].

6. Jenson J. Health care spending and the aging of the population (RS22619) Washington, DC:: Congressional Research Service; 2007. Available from: http://digitalcommons.ilr.cornell.edu/crs/43/.

7. Canbaz S, SÜnter A, Dabak S, Pekșen Y. The prevalence of chronic diseases and quality of life in elderly people in Samsun. Turkish J Med Sci. 2003;33(5):335-40.

8. Felker B, Katon W, Hedrick SC, Rasmussen J, McKnight K, McDonnell $\mathrm{MB}$, et al. The association between depressive symptoms and health status in patients with chronic pulmonary disease. Gen Hosp Psychiatry. 2001;23(2):56-61. [PubMed: 11313071].

9. Bonomi AE, Patrick DL, Bushnell DM, Martin M. Validation of the United States' version of the World Health Organization Quality of Life(WHOQOL) instrument.JClin Epidemiol. 2000;53(1):1-12. [PubMed: 10693897].

10. Simmons L. Dorthea Orem's self care theory as related to nursing practice in hemodialysis. Nephrol Nurs J. 2009;36(4):419-21. [PubMed: 19715109].

11. Demura S, Sato S. Relationships between depression, lifestyle and quality of life in the community dwelling elderly: a comparison between gender and age groups. J Physiol Anthropol Appl Human Sci. 2003;22(3):159-66. [PubMed: 12808229].

12. Osada H, Shibata H, Haga H, Yasumura S. Relationship of physical condition and functional capacity to depressive status in person aged 75 years [ in Japanese]. Nihon Koshu Eisei Zasshi. 1995;42(10):897-909. [PubMed: 8520045].

13. Fassino S, Leombruni P, Abbate Daga G, Brustolin A, Rovera GG, Fabris F. Quality of life in dependent older adults living at home. Arch Gerontol Geriatr. 2002;35(1):9-20. [PubMed: 14764339].

14. Meleis AI. Nursing Theories. Philadelphia: lippincot Co; 2005.

15. Memarian R. Application of nursing concepts and theories [ in Persian ]. Tehran: Center of Scientific Publications in Tarbiat Modares University; 2008.

16. George JB. Nursing Theories: the base for professtional nursing practice. 6 ed. California State University Fullerton: Pearson Education; 2011.
17. Salar AR, Ahmadi F, Faghihzadeh S. Study of effectiveness of continuous care consultation on the quality of life of elderly clients [in Persian]. Zahedan J Research Med Sci. 2004;5(4):261-7.

18. Ballesteros RF. Quality of life: the differential conditions. Psychology in Spain. 1998(2):57-65.

19. Urciuoli O, Dello Buono M, Padoani W, De Leo D. Assessment of quality of life in the oldest-olds living in nursing homes and at home. Arc Gerontol Geriat. 1998;26:507-14. doi:10.1016/s0167-4943(98)80074-5.

20. Kang YS, Kim ES, Gu MO, Eun Y. A study on the health status and the needs of health-related services of female elderly in an urban-rural combined city [in Korean]. J kore Public Health Nurs. 2003;17(1):47-57.

21. Yousefy AR, Ghassemi GR, Sarrafzadegan N, Mallik S, Baghaei AM, Rabiei K. Psychometric properties of the WHOQOL-BREF in an Iranian adult sample. Community Ment Health J. 2010;46(2):139-47. doi: 10.1007/s10597-009-9282-8. [PubMed: 20063062].

22. Nejat S, Montazeri A, Holakouie Naieni K, Mohammad K, Majdzadeh SR. The World Health Organization quality of Life (WHOQOL-BREF) questionnaire: Translation and validation study of the Iranian version [in Persian]. J Sch Public Health Inst Public Health Res. 2006;4(4):112.

23. Baraz S, Rostami M, Farzianpor F, Rasekh A. Effect of Orem Self Care Model on ederies' quality of life in health care centers of Masjed Solaiman in 2007-2008 [in Persian]. Arak Med Univ J. 2009;12(2):51-9.

24. Shahbazzadeghan B, Farmanbar RA, Ghanbari A, Atrkar Roushan Z, Adib M. The effect of regular exercise on self-esteem in elderly residents in nursing homes. J Ardabil Univ Med Sci. 2009;4(8):387-93.

25. Mirsaeedi ZS, Eftekhar ardebili H, Nouri jalyani KA. Effect of a self care program on quality of life of the elderly clients covered by health centers of Southern of Tehran [in Persian]. J Sch Public Health Inst Public Health Res. 2013;10(4):17-32.

26. Heidari M, Shahbazi S. Effect of self-care training program on quality of life of elders [in Persian]. Iran J Nursing. 2012;25(75):1-8.

27. Dickson VV, Howe A, Deal J, McCarthy MM. The relationship of work, self-care, and quality of life in a sample of older working adults with cardiovascular disease. Heart Lung. 2012;41(1):5-14. doi: 10.1016/j.hrtlng.2011.09.012. [PubMed: 22079043].

28. Lord SR, Castell S. Physical activity program for older persons: effect on balance, strength, neuromuscular control, and reaction time. Arch Phys Med Rehabil. 1994;75(6):648-52. [PubMed: 8002763].

29. Kane RA. Long-term care and a good quality of life: bringing them closer together. Gerontologist. 2001;41(3):293-304. [PubMed: 11405425]. 